\title{
INVESTIGATION OF TEASING, SELF-CONFIDENCE AND DEPRESSION LEVELS IN PRIMARY SCHOOL CHILDREN
}

\author{
Medine Yılmaz, Assoc. Prof. ${ }^{1}$, Feyza Dereli, Lect. ${ }^{1}$, Gülçin Uyanık, RA ${ }^{1}$, Gamze Kundakçı, RA ${ }^{1}$, \\ Jülide Yıldırım Duman, Asst. Prof. ${ }^{1}$ \\ ${ }^{1}$ Izmir Katip Celebi University, Health Sciences Faculty, Nursing Department, Turkey
}

\section{OBJECTIVE:}

Teasing which is common among children and adolescents is a universal problem. The primary purpose of this study was to determine the prevalence of teasing behaviors, and levels of self-confidence and depression in primary school children aged 11-14 years.

\section{METHOD:}

The study was conducted with 1796 students between October 2017 and March 2017 in four primary schools located in places with similar socioeconomic levels.

The study data were collected with the Child / Adolescent Teasing Scale, Piers-Harris Children's SelfConcept Scale and Children's Depression Scale. The data were analyzed with the non-parametric tests and correlation analysis in SPSS package program.

\section{CONCLUSION:}

The results of the study demonstrated that one out of every four children in the elementary school age was subjected to teasing behavior. Children who were teased had lower self-confidence levels. In order to ensure that school-age children are in complete physical, psychological and social well-being in the school environment, multidisciplinary teams should conduct programs to raise their awareness and to gain them positive attitudes.

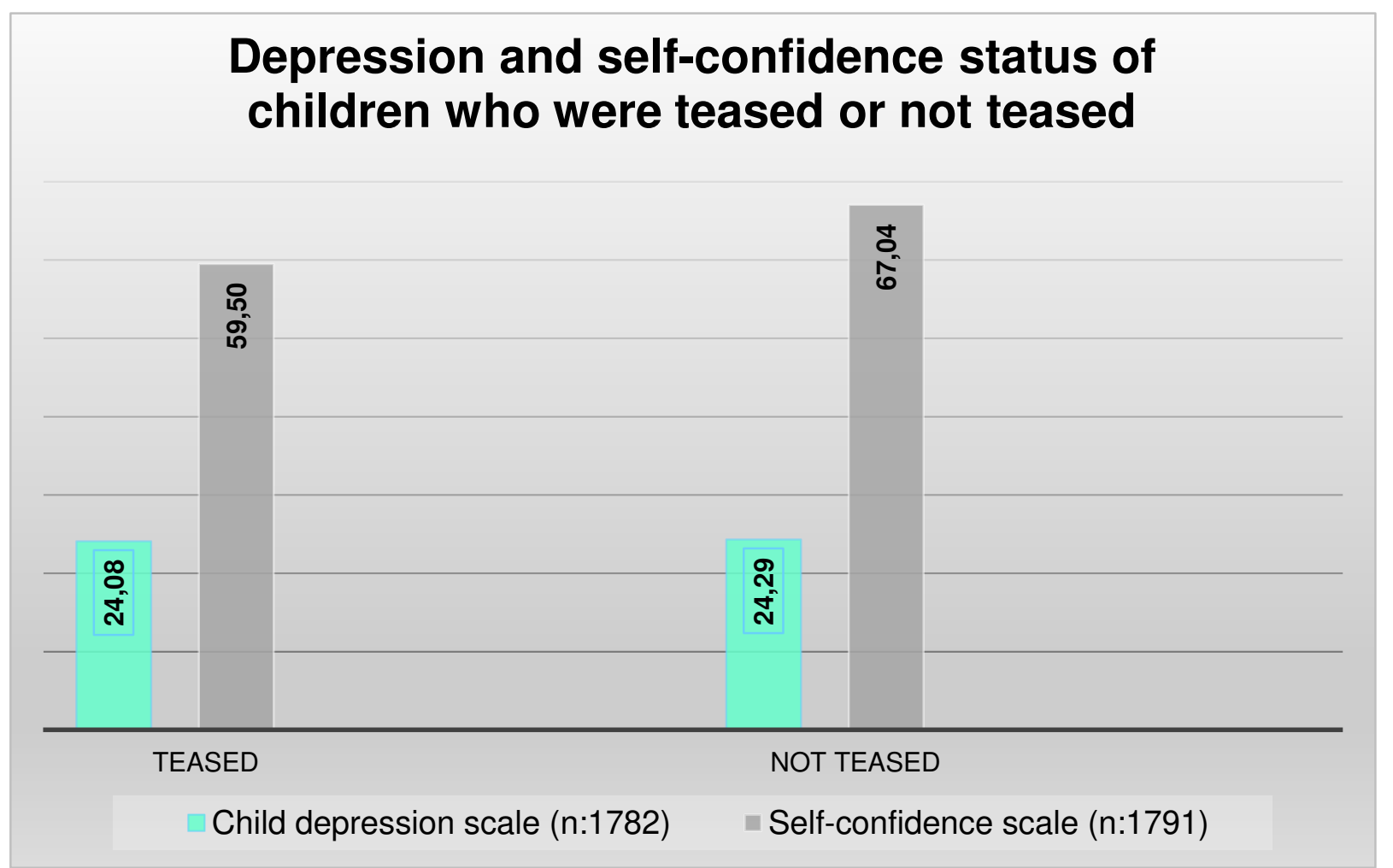

RESULTS:

- The mean age of the participants was $12.2 \pm 1.2$ (1114).

- Of the participating students, $50.4 \%$ were male, $82.3 \%$ had a nuclear family, $88.9 \%$ lived with their parents and $76.5 \%$ reported that they were teased.

- Their mean BMI was $18.9 \pm 3.4$.

- While self-confidence levels were lower among the children who were teased $(p=0.000)$ their depression status did not change ( $p>0.05$ ).

- The participants' self-confidence levels and scores decreased as their teasing $(r=-0.43, p=0.000)$ and depression $(r=-0.18, p=0.000)$ scores increased.

- Children with BMI $\geq 25$ had higher teasing scores and lower self-confidence scores $(p=0.000)$.

- While the girls had higher self-confidence and depression scores, the boys had higher teasing scores $(p<0.01)$.

- Those who lived with their parents had higher selfconfidence and lower teasing scores $(p=0.000)$.

- The students who perceived their school achievement as bad had lower self-confidence and higher teasing scores $(p=0.000)$.

\begin{tabular}{|c|c|c|c|c|c|}
\hline & \multicolumn{2}{|c|}{ Teased } & \multicolumn{2}{|c|}{ Not teased } & \multirow[b]{2}{*}{ Test } \\
\hline & $n$ & $\%$ & $n$ & $\%$ & \\
\hline \multicolumn{6}{|c|}{ Economic condition ( $\mathrm{n}: 1786)$} \\
\hline Very good & 272 & 19.9 & 121 & 28.9 & \multirow{4}{*}{$\begin{aligned} X^{2} & =30,38 \\
p & =0.000\end{aligned}$} \\
\hline Good & 647 & 47.3 & 214 & 51.1 & \\
\hline Medium & 419 & 30.7 & 80 & 19.1 & \\
\hline Bad & 29 & 2.2 & 4 & 1.0 & \\
\hline \multicolumn{6}{|c|}{$\begin{array}{l}\text { Success status of the school perceived by the student } \\
(\mathrm{n}: 1795)\end{array}$} \\
\hline Very good & 427 & 31,1 & 203 & 48,1 & \multirow{4}{*}{$\begin{aligned} X^{2} & =46,56 \\
p & =0.000\end{aligned}$} \\
\hline Good & 562 & 41,0 & 151 & 35,8 & \\
\hline Medium & 304 & 22,2 & 56 & 13,3 & \\
\hline Bad/Awful & 78 & 5,6 & 12 & 2,8 & \\
\hline \multicolumn{6}{|l|}{ BMI (n:1796) } \\
\hline Normal weight & 639 & 46.5 & 226 & 53.6 & \multirow{3}{*}{$\begin{aligned} x^{2} & =21,15 \\
p & =0.000\end{aligned}$} \\
\hline Overweight & 651 & 47.4 & 192 & 45.5 & \\
\hline Obese & 84 & 6.1 & 4 & 0.9 & \\
\hline
\end{tabular}

